\author{
Krzysztof J. Pałko ${ }^{1}$, Andrzej Rogalski ${ }^{1}$, \\ Krzysztof Zieliński ${ }^{1}$, Jarosław Glapiński ${ }^{1}$, Maciej Kozarski ${ }^{1}$, \\ Tadeusz Pałko², Marek Darowski ${ }^{1}$
}

\title{
RC Model-based Comparison Tests of the Added Compliance Method with Computer Simulations and a Standard Method
}

\author{
${ }^{1}$ Institute of Biocybernetics and Biomedical Engineering PAS, \\ Ks. Trojdena 4, 02-109 Warsaw, Poland \\ ${ }^{2}$ Institute of Precision and Biomedical Engineering, \\ Warsaw University of Technology, \\ A. Boboli 8, Warsaw, Poland \\ e-mail:palkot@mchtr.pw.edu.pl
}

\begin{abstract}
Ventilation of the lungs involves the exchange of gases during inhalation and exhalation causing the movement of respiratory gases between alveolars and the atmosphere as a result of a pressure drop between alveolars and the atmosphere. During artificial ventilation what is most important is to keep specific mechanical parameters of the lungs such as total compliance of the respiratory system $C_{p}$ (consisting of the lung and the thorax compliances) and the airway resistance $R_{p}$ when the patient is ventilated. Therefore, as the main goal of this work and as the first step to use our earlier method of added lung compliance in clinical practice was:

1) to carry out computer simulations to compare the application of this method during different expiratory phases, and

2) to compare this method with the standard method for its accuracy.

The primary tests of the added-compliance method of the main lung parameters measurement have been made using the $\mathrm{RC}$ mechanical model of the lungs.
\end{abstract}

Key words: the added compliance method, the end-inspiratory pause technique, the total compliance of respiratory system, the airway resistance, artificial ventilation. 


\section{Introduction}

In our novel method of measurements of the main respiratory system parameters these parameters are determined during the expiratory phase of the ventilation. During our tests two variants of this method were used: in the first one - for the initial phase of the expiratory phase of respiration a small size (0.5-2 1 of volume) extra-added compliance (pneumatic capacitance) and in the second one - for the end of the expiratory phase of the respiration a big size (25; 501 of volume) of the extra-added compliance were considered. The fundamentals of the methodology applied were described in earlier publications [1-3].

The main parameters $\left(C_{p}, R_{p}\right)$ of the respiratory system were determined. The values of the pressure $p_{p}$ at the expiratory phase beginning and the pressure $p_{\infty}=p_{p}-\Delta p$

a)

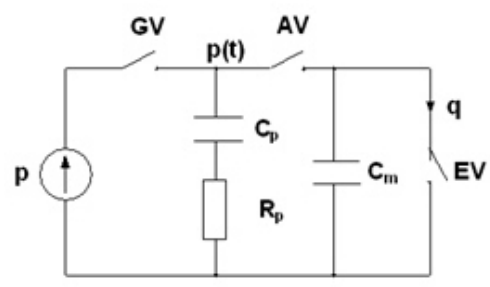

b)

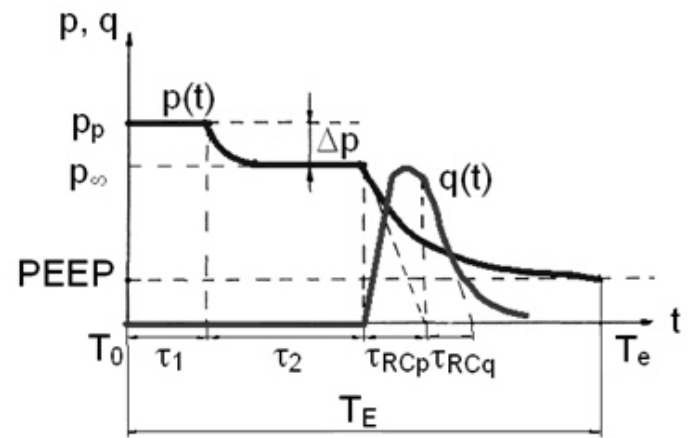

Figure 1. The idea of the presented measurement method: a) the electrical analogue of the measurement system: $p, q$ - respiratory pressure and flow, GV, AV and EV - generator, added compliance and expiratory valves, $C_{p}$ - total compliance of the respiratory system model, $R_{p}$ - airway resistance, $C_{m}$ - added compliance; b) pressure-time $p(t)$ and flow-time $q(t)$ courses in the lung model during the experiments:, PEEP - positive end-expiratory pressure, $\tau_{1}$ - time of the end-inspiratory pause, $\tau_{2}$ - time of the expiration initial stage, $\tau_{\mathrm{RC}}$ - time constant obtained from the pressure-time course, $T_{E}$ - expiration time, $T_{0}, T_{e}$ - times of the initial stage and termination of the measurement, respectively. 
corresponding to the steady state (Fig. 1) were measured to determine the total respiratory system compliance $C_{p}$ according to the following formula:

$$
C_{p}=C_{m} \cdot \frac{p_{\infty}}{\Delta p}
$$

where: $C_{p}, C_{m}$ - the added compliance are expressed in $\mathrm{ml} / \mathrm{kPa}$ or $\mathrm{l} / \mathrm{cm} \mathrm{H}_{2} \mathrm{O}, p_{\infty}, p_{p}$ and $\Delta p$ (the pressure drop at the beginning of the expiratory phase) in $\mathrm{kPa}$ or $\mathrm{cm}_{2} \mathrm{O}$.

To determine the airway resistance $R_{p}$ (by measuring the time constant $\tau_{\mathrm{RC}}$ ), the expiratory flow-time course was analysed Fig. 1) [3].

$$
R_{p}=\frac{\tau_{R C q}}{C_{p}}
$$

where: $R_{p}$ is the airway resistance $\left[\mathrm{kPa} \cdot \mathrm{s} / 1\right.$ or $\left.\mathrm{cm} \mathrm{H}_{2} \mathrm{O} \cdot \mathrm{s} / 1\right]$, and $\tau_{\mathrm{RCq}}$ is the time constant estimated from the flow-time course $q(t)$.

\section{Methods}

\section{The first type of the method tested}

The respiratory gas under a pressure of $p_{i}$ (Fig. 2), obtained from a pressure source and supplied to the respirator, flows to the lungs through the generator valve GV until the lungs become filled up. After this process the added compliance valve AV opens and the respiratory gas under a pressure of $p_{a}$ moves to the extra-added compliance $C_{m}$.

At this time, the earlier discussed pressure drop $\Delta p$ is measured and calculated to determine total compliance of the respiratory system $C_{p}$. The measurement time is very short (about $200 \mathrm{~ms}$ ). Than, the expiratory valve $\mathrm{EV}$ is opened and the flow course $(q)$ is registered to calculate the time constant needed to determine the airway resistance $R_{p}$.

The above respirator was made up of: the pressure regulator, the generator (inspiratory) valve GV, the added compliance valve AV connected to the added compliance $C_{m}$ (the pneumatic capacitance) of the pneumatic circuit of the respirator, and the expiratory valve $\mathrm{EV}$, the pressure sensor, and the pressure drop $\Delta p_{q}$-voltage converter with the Fleisch head playing a role of the flow sensor. The pressure drop $\Delta p_{q}$ is between two pressure values: the pressure of the end-expiratory phase $p_{f}$ and the atmospheric pressure $p_{\text {atm }}$. 


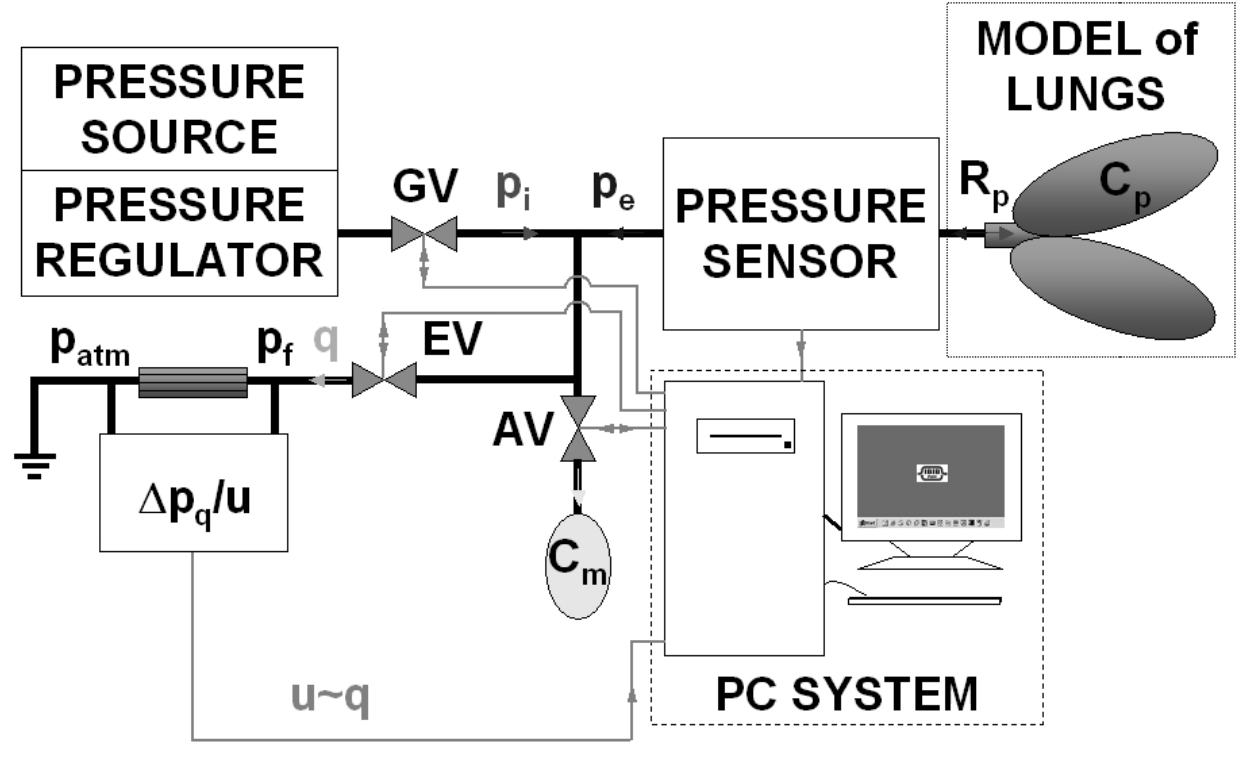

Figure 2. A set-up of the first type of the method tested.

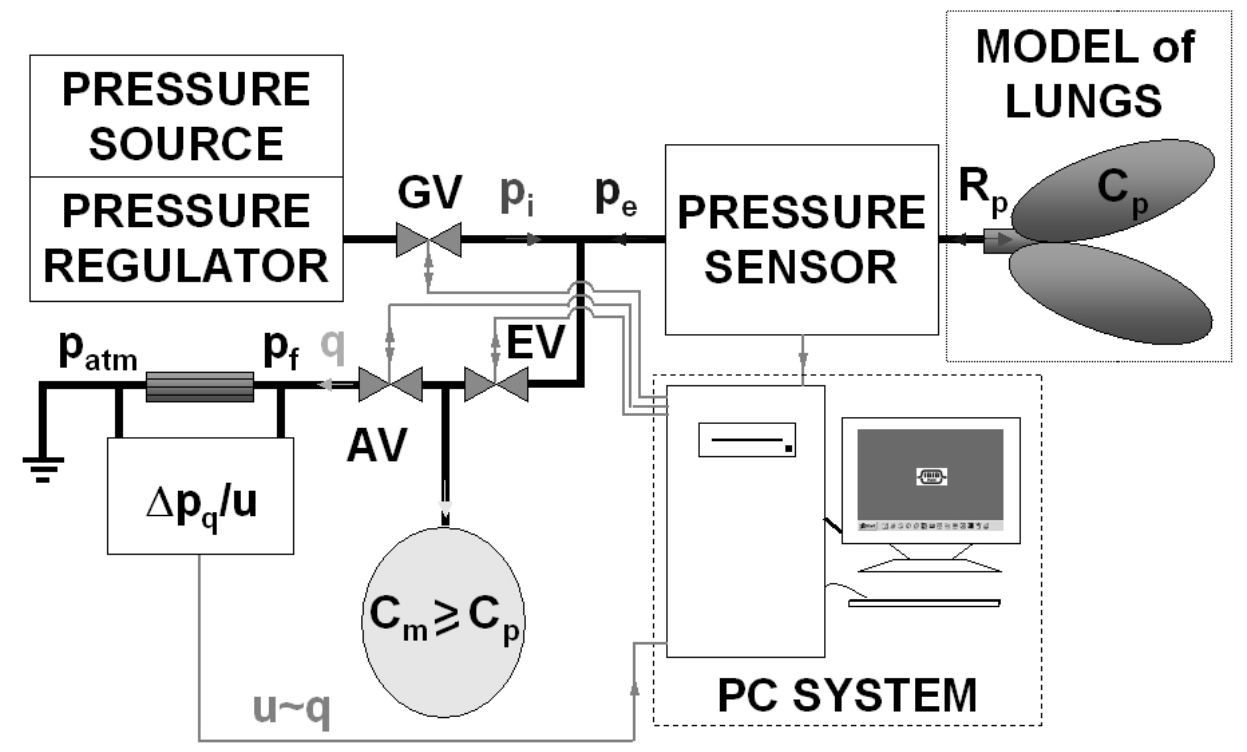

Figure 3. A set-up of the second type of the method tested. 


\section{The second type of the method tested}

The second type of the method tested is presented in Fig. 3. In this case, the lungs are filled with a mixture of gases supplied from the respirator to the extra-added compliance $C_{m}$ through the expiratory valve $\mathrm{VE}$ of the respirator and the external added compliance valve VA, which connects the extra-added compliance $C_{m}$ with the respirator. During this time the pressure drop is calculated to determine the total lung compliance $C_{p}$. The measurement time is longer than that in the first type of the method (about $600 \mathrm{~ms}$ ). At the end of this expiratory phase the flow course is registered to calculate the time constant needed to determine the airway resistance $R_{p}$.

\section{Computer simulation}

As its first aim our work involved comparison tests of the added compliance method with the computer simulations during different expiratory phases. Results were obtained using computer SPICE simulations of two types of the method tested with and without spontaneous breath in the Protel 99SE software (Fig. 4).

a)

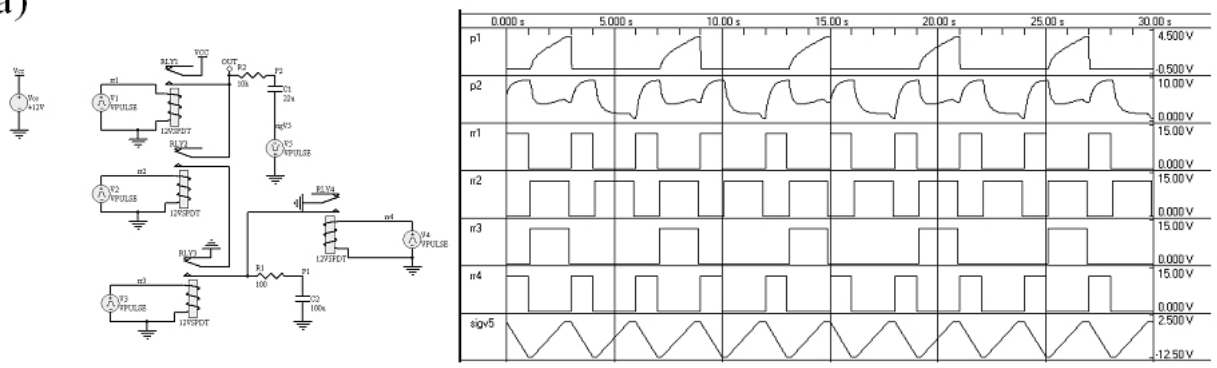

b)

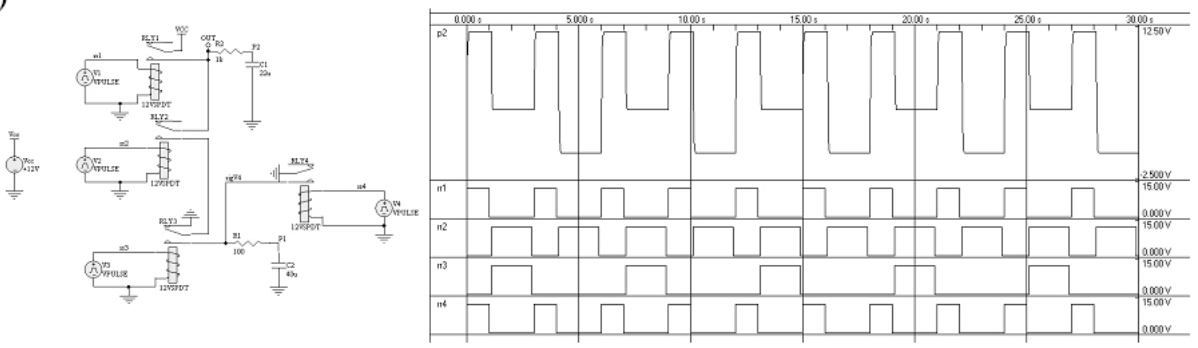

Figure 4. a) Computer simulation of the $1_{\mathrm{st}}$ type of the method tested during artificial ventilation, b) Computer simulation of the $2_{\text {nd }}$ type of the method tested during artificial ventilation 
c)

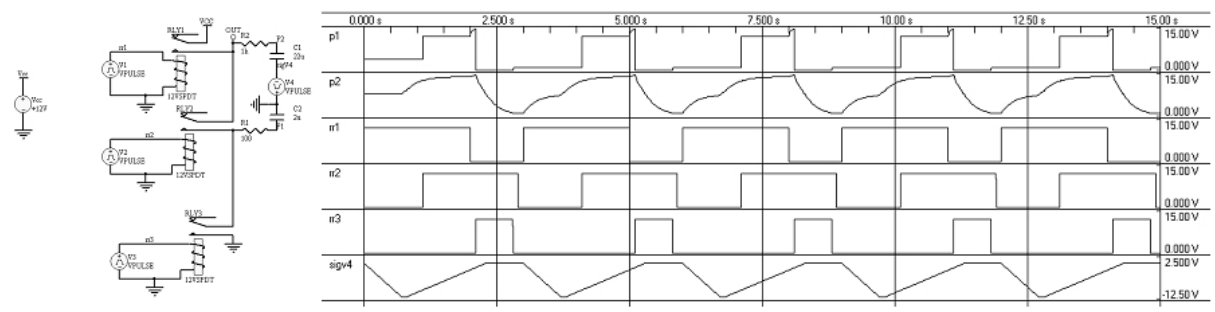

d)

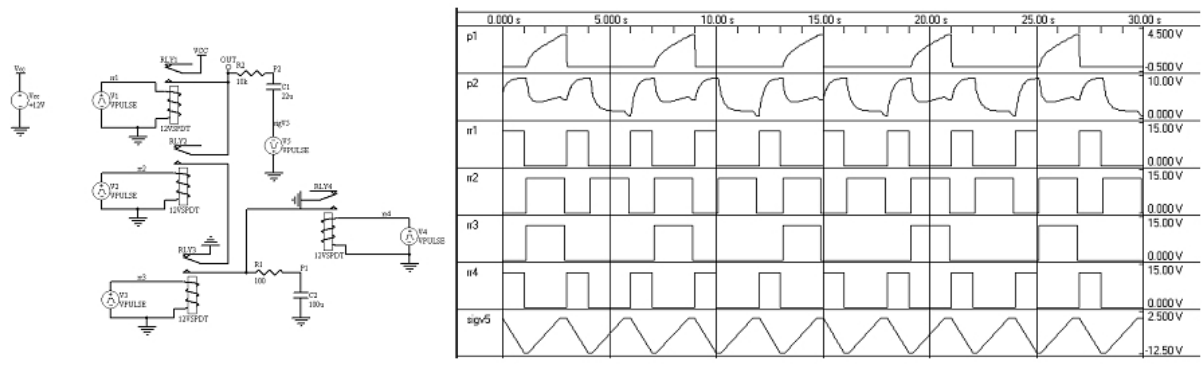

Figure 4. c) Computer simulation of the $1_{\text {st }}$ type of the method tested with spontaneous breath of the patient, d) Computer simulation of the $2_{\text {nd }}$ type of the method tested with spontaneous breath of the patient.

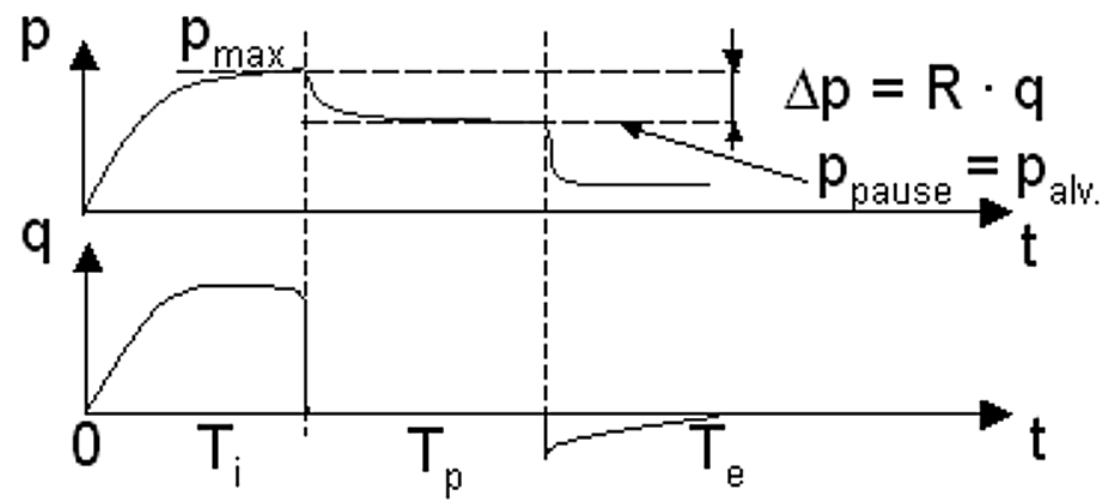

Figure 5. The estimation of the main parameters of the respiratory system from pressure and flow courses of the end-inspiratory pause method. 


\section{Standard method}

To compare the results of our method with the standard method, the end-inspiratory pause technique was used.

The $\mathrm{RC}$ model was connected to the $\mathrm{CO}_{2} \mathrm{SMO}$ Plus (Novametrix) to measure the total compliance of the respiratory system and the airway resistance. Figure 5 presents the way of determining these parameters from the pressure and flow courses using the standard method.

\section{Results and Discussion}

\section{The compliance of the respiratory system}

The results obtained by our method compared with the standard method have shown that the method is satisfactory in evaluating the total compliance of the respiratory system with the acceptable accuracy. There may, however, be a problem involving the estimated compliance of the respiratory system, observed in computer simulations during the active spontaneous breath of the patients that could complicate the measurements, depending on the phase of expiration.

\section{Airway resistance}

The time constant $\tau_{\mathrm{RCp}}$ may easily be found from the pressure curve shown in Fig. $1 \mathrm{~b}$. Thus it may be possible to calculate the airway resistance $R_{p}$ contributing to the time constant $\tau_{\mathrm{RCp}}$ expressed as

$$
\tau_{R C q}=\left(R_{p}+R_{A V}\right) \cdot\left(\frac{C_{p} \cdot C_{m}}{C_{p}+C_{m}}\right) \approx\left(R_{p}+R_{A V}\right) \cdot C_{m} ; \quad C_{m}<<C_{p}
$$

In reality, the calculation of the airway resistance $R_{p}$ is very difficult because - resistance $R_{A V}$ of valve $\mathrm{AV}$ is much greater than the airway resistance $R_{p}\left(R_{A V}>>R_{p}\right)$, - $R_{A V}$ is mostly nonlinear and variable as a function of both time and flow.

The situation becomes much easier if $R_{p}$ is calculated from the flow curve (see Fig. $1 b)$. Then the time constant $\tau_{\mathrm{RCq}}$ is given as 


$$
\tau_{R C q} \approx\left(R_{p}+R_{A V}\right) \cdot\left(C_{p}+C_{m}\right)
$$

where $R_{E V}$ is the resistance of valve $\mathrm{EV}$, but $R_{p}>R_{E V}$ and then $R_{p}$ can be calculated to an acceptable accuracy. We are still working to develop the most efficient method of flow-time courses $q(t)$ analysis so as to calculate the airway resistance $R_{p}$.

The new measurement system turned out to be better than the old one $[1,2,3]$ because of its relative simplicity, smaller disturbances introduced into the respiratory system and simpler data analysis, especially when lung compliance measurements are concerned. The results of the compliance of the respiratory system in both methods are comparable.

Assessing the results obtained, it is necessary to emphasize that the physical model of the lungs investigated was, from the point of view of the disturbing influence of the thermodynamic process, much more disadvantageous in comparison with natural lungs. In the lungs, the so-called "pneumatic compliance" component undergoing the thermodynamic effect was much smaller (by about $80 \%$ ) than the "tissue compliance" and was not influenced by thermodynamic effects.

\section{Conclusions}

The following conclusions can be drawn:

1. The new model-based added compliance method can be useful in estimating mechanical parameters of the lungs for artificially ventilated patients.

2. Two different types of the method tested require suitable time for measurements.

3. The preliminary results encourage us to do further study in order to apply the method in clinical practice.

\section{Acknowledgement}

This work was financed by the State Committee for Science Research (KBN) grant No. 3 T11E 00828 


\section{References}

[1] Darowski M, Jucha A, Kozarski M, Pałko KJ. Analiza krzywej wydechowej dla oceny mechaniki płuc metodą dołączonej podatności. XII Krajowa Konferencja Naukowa Biocybernetyka i Inżynieria Biomedyczna, Warszawa, 2001, tom 1, 252-258.

[2] Darowski M, Pałko KJ, Jucha A, Kozarski M. Expiratory pressure curve analysis for estimation of lungs mechanics. Biocybernetics and Biomedical Engineering 2003; 23(1): 91-102.

[3] Kozarski M, Darowski M, Gumiężny R. Metoda ciśnieniowa dołączonej podatności w ocenie parametrów mechanicznych płuc. XI Krajowa Konferencja Naukowa Biocybernetyka i Inżynieria Biomedyczna, Warszawa, 1999, tom 1, 197-202. 